\title{
Intranasal Midazolam May Prevent Gagging Reflex: a Case Report
}

\author{
Meral Arslan Malkoc', Necla Demir ${ }^{2}$, Zehra Ileri' ${ }^{3}$, Aybuke Erdur ${ }^{3}$, Seza Apiliogullari ${ }^{4}$ \\ ${ }^{1}$ Department of Prosthodontics, Faculty of Dentistry, İnönü University, Malatya, Turkey. \\ ${ }^{2}$ Department of Prosthodontics, Faculty of Dentistry, Selçuk University, Konya, Turkey. \\ ${ }^{3}$ Department of Orthodontics, Faculty of Dentistry, Selçuk University, Konya, Turkey. \\ ${ }^{4}$ Department of Anesthesia and Intensive Care, Faculty of Medicine, Selçuk University, Konya, Turkey.
}

\author{
Corresponding Author: \\ Zehra İleri \\ Selçuk University, Faculty of Dentistry, Department of Orthodontics \\ 42075 Konya \\ Turkey \\ Phone: +903322231163 \\ Fax: +903322410062 \\ E-mail: zehra.ileri@gmail.com
}

\begin{abstract}
Background: Gagging can become a conditioned response that makes dental treatment difficult or impossible for both the individual and the dentist. The aim of this study is to report a 50 year old female and two children (15 and 11 years old) with exaggerated gag reflex referred to Faculty of Dentistry of Selçuk University.

Methods: During obtaining records, taking impression procedure was elicited the patients' hypersensitive gagging reflex. Therefore, it was decided to administer intranasal midazolam to facilitate the taking of accurate dental impressions. After given verbal information about the procedure, $2.5 \mathrm{mg}$ intranasal midazolam (Demizolam, Dem Medikal, Istanbul) were applied incrementally in both nostrils.

Results: Five minutes later; patients had no gagging reflex and allowed the clinician to take satisfying impressions. No serious adverse effects were observed and the patients remained cooperative during the entire procedure which was completed to the full satisfaction of all involved. The short absorption time and the fast relief process of anaesthetics transferred to the systemic circulatory system are important advantages of nasal application.

Conclusions: Intranasal midazolam may be very useful for the treatment of gag reflex probably effecting on the depression of upper airway reflex sensitivity.
\end{abstract}

Keywords: dental impression technique; dental anesthesia; gagging; midazolam.

Accepted for publication: 6 September 2013

To cite this article:

Malkoc MA, Demir N, Ileri Z, Apiliogullari S. Intranasal Midazolam May Prevent Gagging Reflex: a Case Report.

URL: http://www.ejomr.org/JOMR/archives/2013/3/e5/v4n3e5ht.pdf

doi: $10.5037 /$ jomr.2013.4305 


\section{INTRODUCTION}

The gag reflex is a physiological response which safeguards the airway from foreign bodies. The aetiology of gagging is complex and not fully understood. Gagging can become a conditioned response that makes dental treatment difficult or impossible for both the individual and the dentist. It can result in the avoidance of dental care [1].

Clinicians successfully treat many patients with mild gagging problems using only minor procedural modifications or behaviour techniques. Generally, the ultimate goal for patients is to make routine dental care possible by helping them 'unlearn' the behaviour that leads to gagging [2]. Therefore, strategies to overcome the gag reflex in treatment have focused on behaviour modification using systemic desensitization and distraction methods [ $\underline{3}]$. Some patients suffered from such severe gagging that behaviour techniques did not sufficiently reduce gagging in dentistry. In these patients pharmacological management (sedatives [propofol, midazolam, nitrous oxide e.g.], antihistamine, or parasympathetic depressants) was thought to be the last alternative to eliminate the reflex [4-6].

We present three cases which describe the rehabilitation of a female and two paediatric patients who have exaggerated gag reflex requiring prosthetic and orthodontic procedures with the help of intranasal midazolam. This effect may focuses on the inhibitory effect on gagging reflex.

\section{CASE DESCRIPTION AND RESULTS}

\section{Case 1}

A 50 year old, $65 \mathrm{~kg}$ female patient was referred to the Prosthetic Department of Selçuk University for rehabilitation of their oral function and aesthetic. She had malformed anterior teeth in the maxilla and left first

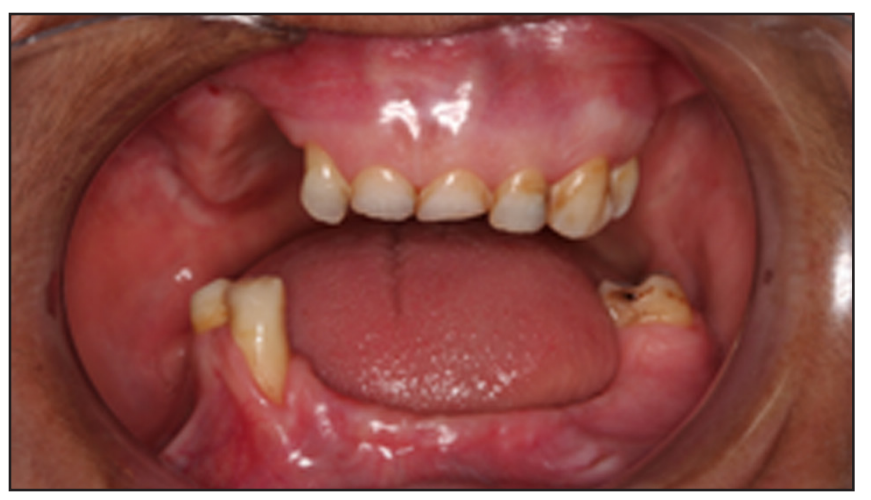

Figure 1. Initial intraoral photograph of patient 1. molar present in the mandible. She had deeply resorbed alveolar ridges. The treatment was planned as providing partial removable dentures retained with fixed partial dentures. She had hypersensitive gag reflex during taking impression. Intranasal midazolam $2.5 \mathrm{mg}$ (Demizolam, Dem Medikal, Istanbul) was employed to facilitate the taking of accurate dental impressions without gagging during the whole procedure by the anaesthesiologist. The patient was given verbal information about the procedure at an assessment visit prior to the impression appointment. The patient had no gag reflex and allowed the dentist to apply the impression tray accurately in the mouth.

The duration of procedure was 3 minutes. The patient was controlled after sedation for 45 minutes before she was discharged. In addition, planning for "horse-shoe" palatal connector reduced palatal coverage area, thereby, providing less interference for tongue and reduced gag reflex (Figure 1 and 2).

\section{Case 2}

A 15 year old, $56 \mathrm{~kg}$ child patient was referred to the Prosthetic Department of Selçuk University. Patient was suffering from chewing dysfunction resulting from maxillary tooth agenesis and deficiency. The definitive treatment plan included fabrication of a partial maxillary removable denture. He did not allow the dentist to put the tray into his mouth and this encouraged us to administer midazolam intranasally for its inhibitory effect on gagging. His parent was also given verbal information about the procedure. Intranasal midazolam $2.5 \mathrm{mg}$ (Demizolam, Dem Medikal, Istanbul) were applied incrementally in both nostrils. Patient's behaviour was excellent during the impression phase. Patient was able to overcome his gagging reflex and completed the treatment by the help of midazolam.

\section{Case 3}

An 11 year old, $45 \mathrm{~kg}$ child patient was referred to

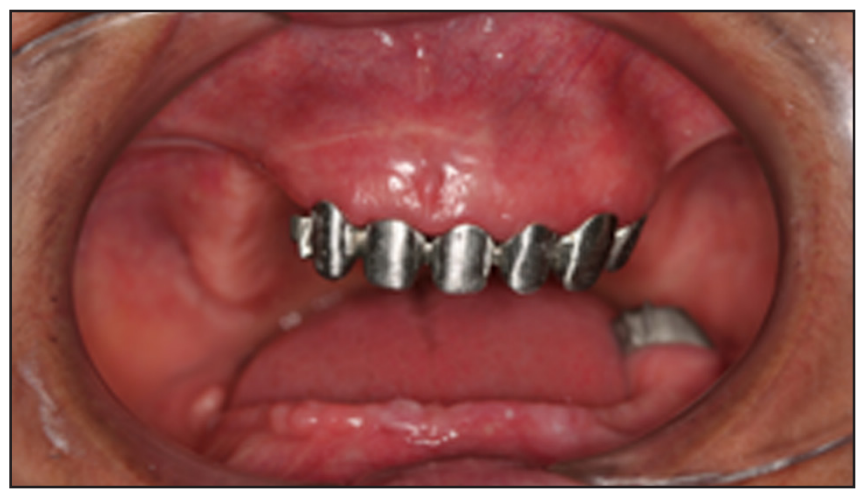

Figure 2. Metal framework try-in procedure of patient 1 . 
the Orthodontic Department of Selçuk University. It was learnt from the medical history of the patient that he used regular medication for hyperactivity. In extraoral clinical examination, it was observed that the patient had a skeletal Class III malocclusion and concave profile. In the intraoral and radiographic examination, it was detected that the patient was in mixed dentition stage and Angle class II molar relationship on both sides. According to the facial midline, the maxillary midline was $1 \mathrm{~mm}$ on the left and the mandibular midline was $1 \mathrm{~mm}$ on the right. Overjet was $2 \mathrm{~mm}$ and overbite was $2.5 \mathrm{~mm}$. The orthodontic treatment plan included nonextraction treatment after using face mask.

During obtaining initial records, taking impression procedure was elicited patient's hypersensitive gagging reflex. Therefore, it was decided to administer intranasal midazolam in advantage to take precise dental impressions without gagging during the whole procedure. After patient's parents were given verbal information about the procedure, $2.5 \mathrm{mg}$ intranasal midazolam (Demizolam, Dem Medikal, Istanbul) were applied incrementally in both nostrils. Five minutes later, the patient felt himself relaxed and the level of sedation was sufficient to take dental impression. We experienced the benefit of intranasal midazolam to facilitate taking precise dental impressions in problematic gagging patients intolerable to dental therapy. All patients suffered moderate burning in the nostril after delivery of intranasal midazolam (Figure 3 and 4).

\section{DISCUSSION}

Retentive denture prosthesis is a major factor in achieving a successful result when providing partial removable dentures. The best results are obtained when the prosthesis bases contain all anatomic landmarks in the upper and lower arches. This is really complicated when the patients' anamnesis tells us the difficulty with the impression phase of treatment due to a hypersensitive gag reflex. Intranasal midazolam may be safely used to facilitate the taking of dental impressions in these patients.

In the aetiology of gagging, the factors involved in its development are divided into psychological

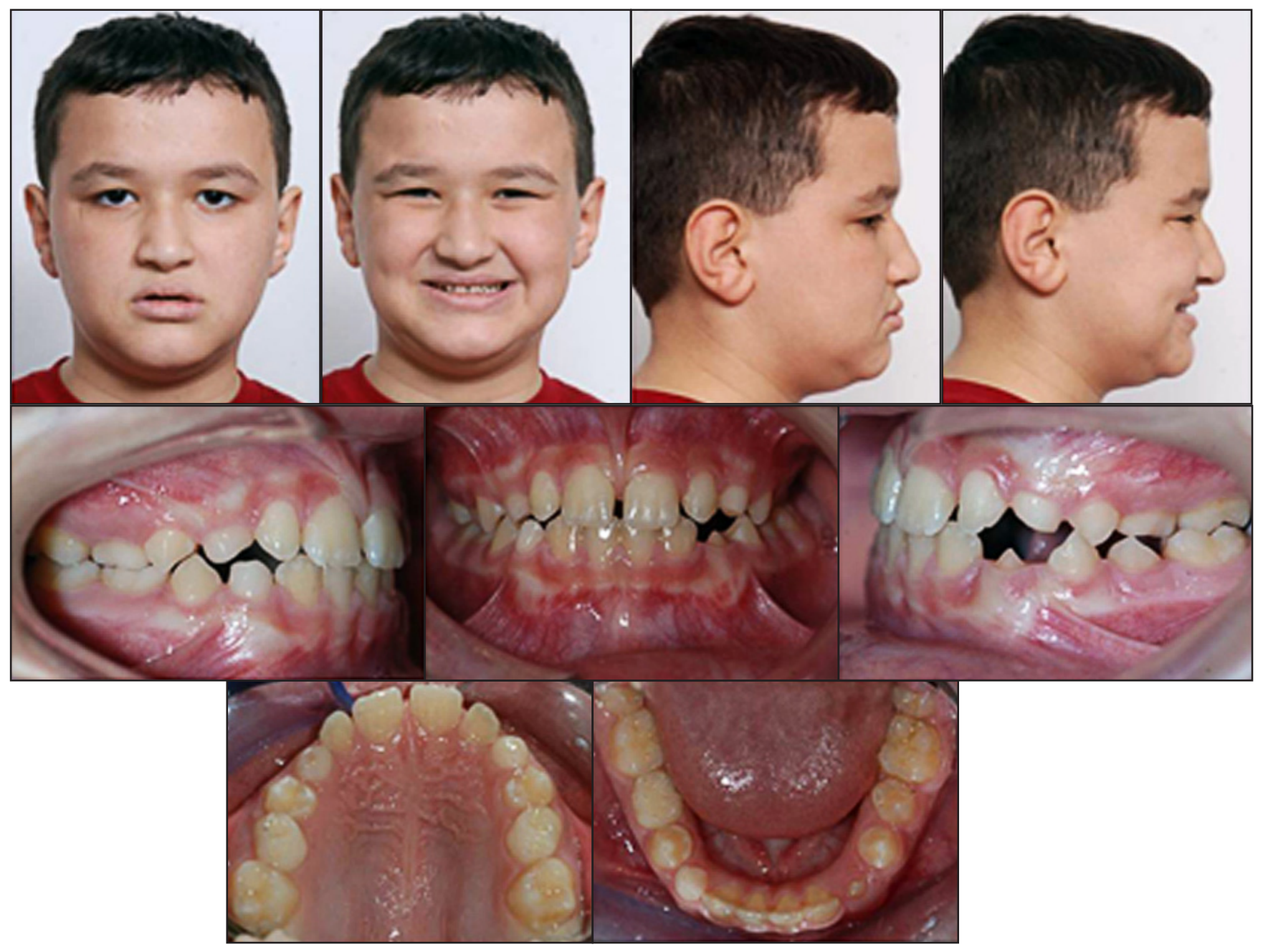

Figure 3. Initial extraoral and intraoral photographs of patient 3. 


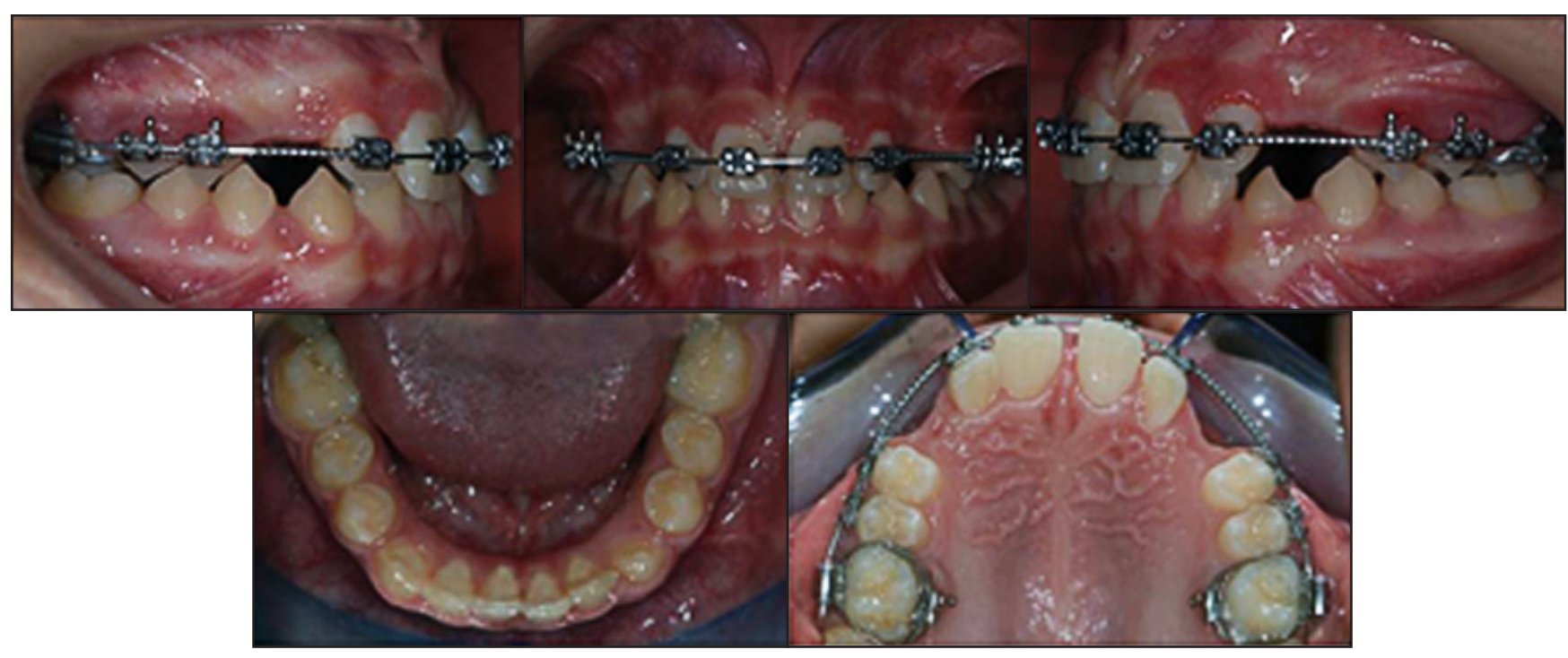

Figure 4. Intraoral photographs of patient 3 after bracket bonding.

and somatogenic $[\underline{7}, \underline{8}]$. Anatomical abnormalities or neural hypersensitivity in the oropharynx have been identified as somatogenic factors in the development of the gag reflex [7]. In a previous study by Saita et al. [9] , it was reported that psychological factors were identified in all patients with strong anxiety indicated as the probable cause of the gag reflex. However same authors were stated that the gag reflex was caused by touching the oral mucosa in most of patients with some difference in degree of severity. In our patients, a pre-treatment oral examination was not performed to determine gagging severity but a hypersensitive gag reflex was developed during taking impression in all patients. However it may not be easy to distinguish between two aetiological factors because physical stimuli may still provoke gagging of psychogenic origin [7].

A number of techniques for reduction of gagging have been suggested, including distraction of patient's attention from the dental procedure, relaxation, hypnosis, acupuncture, drugs and general anaesthesia (GA). GA is also conducted in a patient with extremely problematic gagging who is intolerable to dental therapy under intravenous sedation. The advantage of GA is complete elimination of the reflex, but costs should be considered in comparison to the benefit of dental care [10]. Previous case reports also showed the adjustment to dental care $[\underline{3}, 11]$. As another alternative, inhalation sedation using nitrous oxide is the most common method of delivery of conscious sedation in dentistry. Nitrous oxide inhalation sedation was shown to be useful for control of the gagging reflex [11]. Nitrous oxide is a commonly used pharmacologic agent but has the main disadvantage in especially children of being a nasal inhalation agent [12]. One of the popular medications available to the dentist for use in children is midazolam.
Midazolam is a short-acting benzodiazepine with a short half-life, in children, of two hours compared to 18 hours for diazepam. Midazolam has been used for preoperative sedation by the intramuscular, rectal, oral and nasal routes [13]. The injections are painful and injection procedure is the most common fear of the children. The anaesthetics used orally and rectally start to relieve symptoms in a longer time. The recovery is a slow process after oral medication. Children are prone to vomit or spit out the anaesthetics given orally $[\underline{14}, \underline{15}]$. This technique has advantages when compared with oral administration as the bioavailability of intranasal administered midazolam is approximately $55 \%$, compared with $15 \%$ when administered orally $[16,17]$. The rate of onset and recovery are more rapid, but intranasal burning is the main disadvantage of the nasal application of midazolam [18].

The nasal anaesthesia is popular as a useful and safe way. The short absorption time and the fast relief process of anaesthetics transferred to the systemic circulatory system are important advantages of nasal anaesthesia. Our patients' gagging behaviours was modified with the use of intranasal midazolam. No serious adverse effects were observed and the patients remained cooperated in the impression phase as in the beginning of the treatment; they had no gagging during the entire procedure which was completed to the full satisfaction of all involved. These three cases showed that intranasal midazolam could be very effective treatments in exaggerated gag reflex in paediatric and adult patients.

For some patients, however, severe gagging can be elicited by the dentist's fingers or instruments contacting the oral mucosa or even by nontactile stimuli, for example, patients seeing the dentist or remembering a previous dental experience [7]. Taking impression becomes a very challenging procedure for 
clinicians to handle. Some clinicians swab the sensitive mucosal areas with topical anaesthetics, whereas others suggest that impressions should be made under general anaesthesia or hypnosis. Anaesthetic sprays are difficult to control and their use may result in increased risk of toxicity [5]. Intranasal midazolam has been found to be effective in doses ranging from 0.2 to $0.6 \mathrm{mg} / \mathrm{kg}$ (maximum $15 \mathrm{mg}$ ) when used for conscious sedation and as a premedicant for children. In our clinic; $2.5 \mathrm{mg}$ or $5 \mathrm{mg}$ intranasal midazolam is being used according to the anaesthesiologists' preference in adults and $0.5 \mathrm{mg} / \mathrm{kg}$ (maximum $10 \mathrm{mg}$ ) in child. In this clinical report; $2.5 \mathrm{mg}$ intranasal midazolam was preferred for all patients. The reason of this quantity of dose preference for the child patients is their weights (56 and $45 \mathrm{~kg}$ ) and no sedation effect is required for them. The beneficial effects of midazolam include sedation, anxiolysis, and reduction of postoperative vomiting $[\underline{15}, \underline{19}, \underline{20}]$.

A written consent should be obtained prior to application midazolam. Our patients were given written consent before orthodontic and prosthetic treatment and also verbal information about the midazolam procedure at an assessment visit prior to the impression appointment. Premedication with oral midazolam has shown to be more effective than parental presence or placebo in reducing gagging anxiety and improving compliance at induction of anaesthesia $[\underline{19,20]}$. Intranasal drug administration is relatively quick, simple, and may have benefits over transmucosal routes or rectal administration, which requires more patient cooperation.
And, intravenous way is not needed.

The use of conscious sedation with inhalational, oral, or intravenous agents may temporarily eliminate gagging during dental treatment [21]. In dental procedures; midazolam is accepted as one of the most effective agents to reduce gagging reflex due to its sedative effects [21]. In a study by Murphy et al. [22] which has investigated the effect of intravenously administered midazolam on the sensitivity of upper airway reflexes in volunteers, the authors concluded that midazolam produced significant depression of upper airway reflex sensitivity. And this conclusion may also explain our clinical results.

\section{CONCLUSIONS}

Besides the sedative effect of midazolam, the intranasal midazolam was found to be very useful for taking impressions probably effecting on the depression of upper airway reflex sensitivity. Further investigations by using quantitative methods are needed to be done to clearly prove this effect of midazolam in dentistry.

\section{ACKNOWLEDGMENTS AND DISCLOSURE STATEMENTS}

The authors report no conflicts of interest related to this study.

\section{REFERENCES}

1. Fiske J, Dickinson C. The role of acupuncture in controlling the gagging reflex using a review of ten cases. Br Dent J. 2001 Jun 9;190(11):611-3 [Medline: 11441900] [doi: 10.1038/sj.bdj.4801053]

2. Wilks CG, Marks IM. Reducing hypersensitive gagging. Br Dent J. 1983 Oct 22;155(8):263-5. [Medline: 6580017] [doi: $10.1038 /$ sj.bdj.4805203]

3. Robb ND, Crothers AJ. Sedation in dentistry. Part 2: Management of the gagging patient. Dent Update. 1996 Jun;23(5): 182-6. [Medline: 8948179$]$

4. Yoshida H, Ayuse T, Ishizaka S, Ishitobi S, Nogami T, Oi K. Management of exaggerated gag reflex using intravenous sedation in prosthodontic treatment. Tohoku J Exp Med. 2007 Aug;212(4):373-8. [Medline: 17660702] [doi: 10.1620/tjem.212.373] [FREE Full Text]

5. Council on Dental Therapeutics of the American Dental Association: Accepted Dental Therapeutics 40th ed.Chicago: American Dental Association; 1985.

6. Hattab FN, Al-Omari MA, Al-Dwairi ZN. Management of a patient's gag reflex in making an irreversible hydrocolloid impression. J Prosthet Dent. 1999 Mar;81(3):369. Erratum in: J Prosthet Dent. 2005 May;93(5):499. Al-Duwayri, ZN [corrected to Al-Dwairi ZN]. [Medline: 10050127] [doi: 10.1016/S0022-3913(99)70282-9]

7. Bassi GS, Humphris GM, Longman LP. The etiology and management of gagging: a review of the literature. J Prosthet Dent. 2004 May;91(5):459-67. Review. [Medline: 15153854] [doi: 10.1016/j.prosdent.2004.02.018]

8. Conny DJ, Tedesco LA. The gagging problem in prosthodontic treatment. Part I: description and causes. J Prosthet Dent. 1983 May;49(5):601-6. [Medline: 6343586] [doi: 10.1016/0022-3913(83)90381-5]

9. Saita N, Fukuda K, Koukita Y, Ichinohe T, Yamashita S. Relationship between gagging severity and its management in dentistry. J Oral Rehabil. 2013 Feb;40(2):106-11. Epub 2012 Dec 10. [Medline: 23231041] [doi: 10.1111/joor.12014] 
10. Yagiela JA. Making patients safe and comfortable for a lifetime of dentistry: frontiers in office-based sedation. J Dent Educ. 2001 Dec;65(12):1348-56. [Medline: 11780653] [FREE Full Text]

11. Chidiac JJ, Chamseddine L, Bellos G. Gagging prevention using nitrous oxide or table salt: a comparative pilot study. Int J Prosthodont. 2001 Jul-Aug;14(4):364-6. [Medline: 11508093]

12. Varas KG. Pharmacological management of the healthy but uncooperative pre-school child. J Pediatr Dent Care. 2003; 9(2):14.

13. Fuks AB, Kaufman E, Ram D, Hovav S, Shapira J. Assessment of two doses of intranasal midazolam for sedation of young pediatric dental patients. Pediatr Dent. 1994 Jul-Aug;16(4):301-5.5. [Medline: 7937264]

14. Haas DA. Oral and inhalation conscious sedation. Dent Clin North Am. 1999 Apr;43(2):341-59. Review. [Medline: 10331147]

15. Kain ZN, Mayes LC, Wang SM, Caramico LA, Hofstadter MB. Parental presence during induction of anesthesia versus sedative premedication: which intervention is more effective? Anesthesiology. 1998 Nov;89(5):1147-56; discussion 9A-10A. [Medline: 9822003]

16. Veerkamp JS, Gruythuysen RJ, Hoogstraten J, van Amerongen WE. Anxiety reduction with nitrous oxide: a permanent solution? ASDC J Dent Child. 1995 Jan-Feb;62(1):44-8. [Medline: 7775683]

17. Primosch RE, Guelmann M. Comparison of drops versus spray administration of intranasal midazolam in two- and threeyear-old children for dental sedation. Pediatr Dent. 2005 Sep-Oct;27(5):401-8. [Medline: 16435641]

18. Yealy DM, Ellis JH, Hobbs GD, Moscati RM. Intranasal midazolam as a sedative for children during laceration repair. Am J Emerg Med. 1992 Nov;10(6):584-7. [Medline: 1388390] [doi: 10.1016/0735-6757(92)90190-9]

19. Knoester PD, Jonker DM, Van Der Hoeven RT, Vermeij TA, Edelbroek PM, Brekelmans GJ, de Haan GJ. Pharmacokinetics and pharmacodynamics of midazolam administered as a concentrated intranasal spray. A study in healthy volunteers. Br J Clin Pharmacol. 2002 May;53(5):501-7. [Medline: 11994056] [doi: 10.1046/j.1365-2125.2002.01588.x] [FREE Full Text]

20. Kain ZN, Hofstadter MB, Mayes LC, Krivutza DM, Alexander G, Wang SM, Reznick JS. Midazolam: effects on amnesia and anxiety in children. Anesthesiology. 2000 Sep;93(3):676-84. [Medline: 10969300] [doi: 10.1097/00000542-200009000-00016]

21. Kumar S, Satheesh P, Savadi RC. Gagging. N Y State Dent J. 2011 Jun-Jul;77(4):22-7. [Medline: 21894827]

22. Murphy PJ, Erskine R, Langton JA. The effect of intravenously administered diazepam, midazolam and flumazenil on the sensitivity of upper airway reflexes. Anaesthesia. 1994 Feb;49(2):105-10. [Medline: 8129118] [doi: 10.1111/j.1365-2044.1994.tb03363.x]

To cite this article:

Malkoç MA, Demir N, Ileri Z, Apiliogullari S. Intranasal Midazolam May Prevent Gagging Reflex: a Case Report. J Oral Maxillofac Res 2013;4(3):e5

URL: http://www.ejomr.org/JOMR/archives/2013/3/e5/v4n3e5ht.pdf

doi: $10.5037 /$ jomr.2013.4305

Copyright (C) Malkoç MA, Demir N, Ileri Z, Apiliogullari S. Published in the JOURNAL OF ORAL \& MAXILLOFACIAL RESEARCH (http://www.ejomr.org), 1 October 2013.

This is an open-access article, first published in the JOURNAL OF ORAL \& MAXILLOFACIAL RESEARCH, distributed under the terms of the Creative Commons Attribution-Noncommercial-No Derivative Works 3.0 Unported License, which permits unrestricted non-commercial use, distribution, and reproduction in any medium, provided the original work and is properly cited. The copyright, license information and link to the original publication on (http://www.ejomr.org) must be included. 